\title{
TAXA DE UTILIZAÇÃO INDIVIDUAL DO CELULAR NO BRASIL ENTRE 2013 E 2017
}

\section{ARTIGO ORIGINAL}

MELO, João Paulo Calado ${ }^{1}$

FECURY, Amanda Alves ${ }^{2}$

OLIVEIRA, Euzébio de ${ }^{3}$

DENDASCK, Carla Viana ${ }^{4}$

DIAS, Claudio Alberto Gellis de Mattos ${ }^{5}$

MELO, João Paulo Calado. Et al. Taxa de utilização individual do celular no brasil entre 2013 e 2017. Revista Científica Multidisciplinar Núcleo do Conhecimento. Ano 04, Ed. 12, Vol. 07, pp. 30-42. Dezembro de 2019. ISSN: 2448-0959, Link de acesso: https://www.nucleodoconhecimento.com.br/tecnologia/utilizacao-individual

\footnotetext{
${ }^{1}$ Estudante do Curso Técnico em Redes de Computadores, Ensino médio, Campus Macapá, Instituto Federal do Amapá (IFAP).

${ }^{2}$ Biomédica, Doutora em Doenças Topicais, Professora e pesquisadora do Curso de Medicina do Campus Macapá, Universidade Federal do Amapá (UNIFAP).

3 Biólogo, Doutor em Doenças Topicais, Professor e pesquisador do Curso de Educação Física da Universidade Federal do Pará (UFPA).

${ }^{4}$ Teóloga, Doutora em Psicanálise, pesquisadora do Centro de Pesquisa e Estudos Avançados- CEPA.

${ }^{5}$ Biólogo, Doutor em Teoria e Pesquisa do Comportamento, Professor e pesquisador do Colegiado de Química, Campus Macapá, Instituto Federal do Amapá (IFAP).
} 


\section{RESUMO}

Aparelhos celulares utilizam ondas de radio para possibilitar a intercomunicação entre as pessoas. Para poder realizar ligações é preciso pagar para as operadoras de telefonia específicas. Além de ligações existe a possibilidade de acesso a rede mundial de computadores via estes aparelhos. $O$ uso do celular está presente em todas as classes sociais, faixas etárias e gêneros. Este trabalho tem o objetivo de analisar a taxa de utilização individual do celular no Brasil entre 2012 e 2017. Para tanto foi realizada uma pesquisa foi realizada no banco de dados CETIC (https://www.cetic.br/). Os resultados mostram que, entre os indivíduos que possuem aparelho celular, a maioria é do gênero feminino, mora na região Sul ou Centro-Oeste do país e tem faixa etária entre 25 e 34 anos. A maioria dos celulares é habilitado em linhas pré-pagas. No quesito efetuar e receber chamadas, o público feminino é destaque, assim como as regiões Sul e Sudeste e a faixa etária entre 25 e 34 anos. Os dados mostram que o maior acesso a redes sociais se dá pelo público feminino, pela região Sudeste, e pela faixa etária de 16 a 24 anos. Quanto à busca de informações via celular não há distinção entre os gêneros, o maior índice de busca está na região Sudeste e na faixa etária entre 16 e 24 anos. Observa-se que há um aumento na utilização de celulares nas regiões Sul e Sudeste no país, mostrando uma desigualdade em relação à tecnologia. No Brasil não há fortes projetos para combater essa desigualdade social, limitando o acesso à informação e, consequentemente, oportunidade de discernimento ao cidadão comum.

Palavras chave: Celular, Redes Sociais, Pré-pago, Pós-pago.

\section{INTRODUÇÃO}

O telefone celular ou telefone móvel facilita a comunicação entre as pessoas. Esses aparelhos surgiram do desenvolvimento tecnológico dos antigos rádios utilizados em veículos. Eles utilizam ondas de rádio enviadas dentro de uma pequena área (célula). As pequenas áreas formam uma grande área geográfica que se intercomunica, facilitando a transmissão do sinal (GUTIERREZ E CROSSETTI, 2003). 
As ligações telefônicas, celulares são feitas através de um dispositivo sem fio. Para poder realizar ligações é preciso pagar para as operadoras de telefonia específicas (criando um cadastro). Para ocorrer uma ligação via celular entre dois usuários são necessários dois aparelhos e números (códigos matemáticos) que identificam e interligam as linhas (SIQUEIRA E OLIVEIRA, 2016).

O tipo de plano de aluguel de linha telefônica celular mais utilizados pelos brasileiros é denominado pré-pago. Nele o usuário paga antecipadamente os minutos e o limite de acesso a internet. No plano pós-pago o usuário faz um contrato de utilização e é cobrado depois de utilizar os serviços (ligações e internet) (BARCELOS et al., 2015).

$\mathrm{Na}$ internet, desde $\mathrm{o}$ ano 2002, existem locais (sites), que contém páginas, onde a pessoa consegue elaborar e colocar um perfil próprio utilizando fotografias, vídeos e textos (ambientes virtuais) (SCHUMANN et al., 2015). A evolução destes ambientes virtuais é atualmente chamada de rede social (por exemplo Facebook, Instagram, Whatsapp, Twitter e Snapchat). O maior número de usuários nessas aplicações, costumam ser adolescentes (LIRA et al., 2017). Atualmente a redes social virtual principal e mais acessada por tais usuários, é o Facebook (CARRANO, 2017).

Alguns locais oferecem serviços, gratuitos ou não, onde é possível buscar informações sobre praticamente qualquer assunto. Esses locais (sites) são denominados navegadores de busca (ou da internet). (TORRES, 2018). Os navegadores são tipos de programas que exibem páginas (sites). Quando o usuário resolve fazer uma busca sobre qualquer assunto, digita no campo apropriado do navegador sua dúvida (que pode ser uma palavra ou uma frase). A busca então é realizada em computadores chamados de servidores. Servidor é o computador (ou uma rede de computadores) que armazena as informações (conhecimentos) colocadas(os) nele(s) (SOUZA, 2018).

No Brasil, em 2016, 77,1\% da população tinham telefone móvel celular para uso pessoal. A região com maior índice era o Centro-Oeste $(84,6 \%)$, seguido pelas regiões Sul $(82 \%)$, Sudeste $(81,8 \%)$, Nordeste $(68,7 \%)$ e Norte $(65,1 \%)$ (IBGE, 2016$)$. 
O uso do celular está presente em todas as classes sociais e gêneros. No entanto são as mulheres quem tem maior percentual na posse de aparelhos celulares $(78,6 \%)$. Mas nas regiões sudeste e Sul, são os homens quem tem maior quantidade de celulares, com $82,2 \%$ e $82,5 \%$ respectivamente (BARBOSA, 2018). No Brasil, o maior número de pessoas que tem posse de algum aparelho celular é do gênero feminino e está na faixa etária 10 a 59 anos, com exceção dos homens com 60 anos ou mais. $O$ mesmo ocorre nas regiões do Brasil, onde as mulheres têm maior número de posse de celular, com exceção apenas do Sul (IBGE, 2016).

No país as faixas etárias com maior índice de posse de celulares para uso pessoal é a de 25 a 34 anos (88,6\%). Em seguida vem a faixa de 35 a $39(88,2 \%), 40$ a 44 (86,3\%), 20 a $24(86 \%), 45$ a $49(84 \%), 50$ a $54(82,1 \%), 18$ ou $19(81,8 \%), 55$ a 59 (79,5\%), 14 a $17(70 \%), 60$ ou mais $(60,9 \%)$ e, por fim, 10 a 13 anos $(39,8 \%)$ (IBGE, 2016).

\section{OBJETIVO}

Analisar a taxa de utilização individual do celular no Brasil entre 2012 e 2017.

\section{MÉTODO}

A pesquisa foi realizada no banco de dados CETIC (https://www.cetic.br/). Acessando a aba "Pesquisas e Indicadores", foi selecionado a opção "TIC Domicílios" e depois a opção "INDICADORES". Clicou-se em "INDIVÍDUOS". Os anos foram alterados em uma opção cinza no lado direito; descemos no site até encontrarmos a categoria "Telefone Celular", onde foram coletados os dados dos anos entre 2012 e 2017 . A pesquisa bibliográfica foi realizada em artigos científicos, em computadores do Instituto no Instituto Federal de Educação, Ciência e Tecnologia do Amapá, Campus Macapá, situado à Rodovia BR 210 KM 3, s/n - Bairro Brasil Novo. CEP: 68.909-398, Macapá, Amapá, Brasil. Os dados foram compilados no aplicativo Excel, componente do pacote Office da Microsoft Corporation. 


\section{RESULTADOS}

A figura 1 mostra a média da porcentagem de indivíduos que possuem telefone celular entre 2013 a 2017, por regiões do Brasil. As maiores porcentagens encontram-se nas regiões Sul $(88 \%)$ e Centro-Oeste (88\%), seguidas pelas regiões Sudeste $(86 \%)$, Norte $(78 \%)$ e Nordeste $(76 \%)$.

Figura 1 Mostra a média da porcentagem de indivíduos que possuem telefone celular entre 2013 a 2017, por regiões do Brasil.

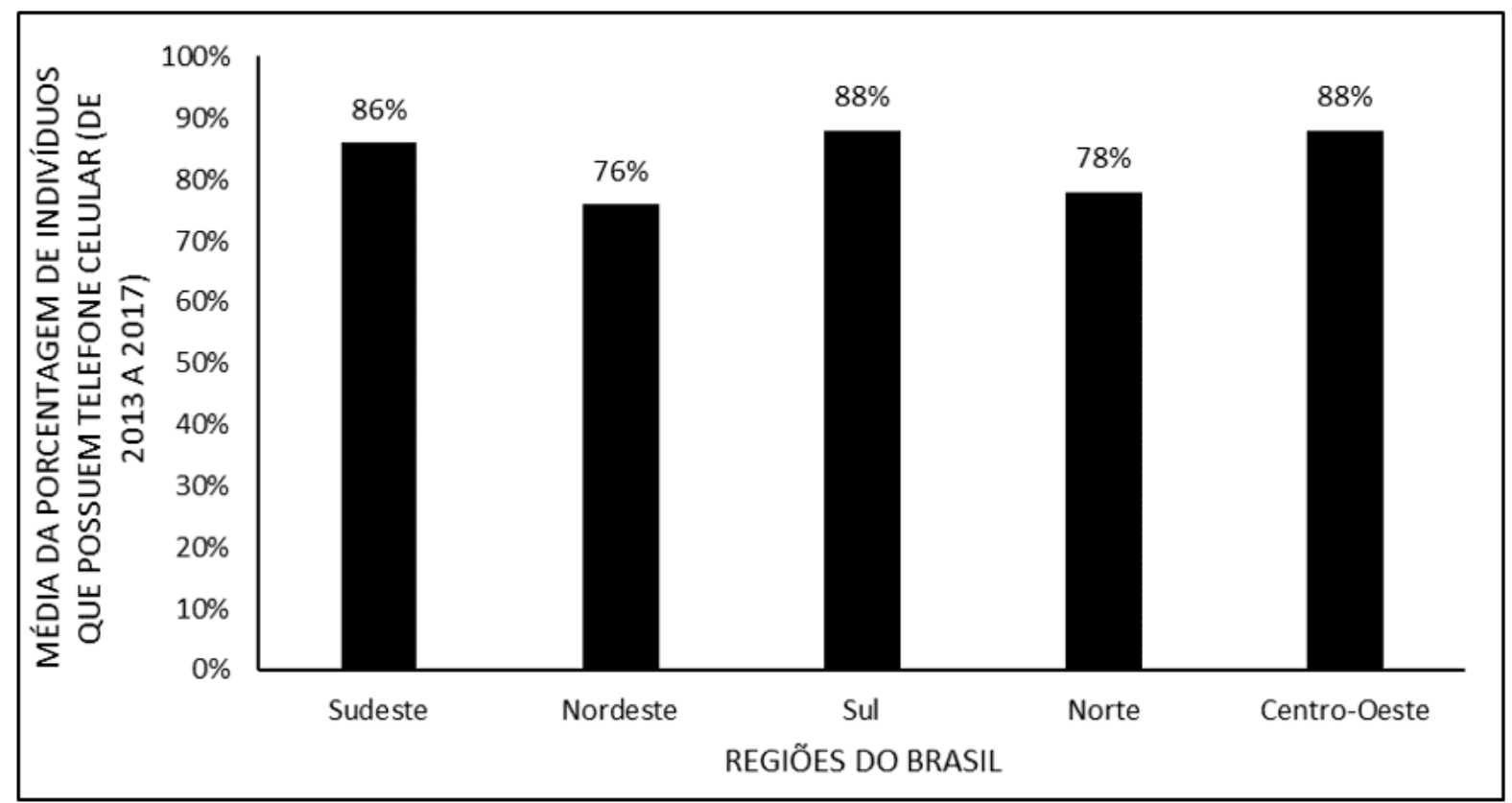

A figura 2 mostra a porcentagem de indivíduos brasileiros que possuem telefone celular entre 2013 e 2017, por gênero. O público feminino é quem mais utiliza o dispositivo móvel (em média 84,4\%) quando comparado com o público masculino (82\%). Entre os anos nota-se uma estabilidade na porcentagem de uso. 
Figura 2 Mostra a porcentagem de indivíduos brasileiros que possuem telefone celular entre 2013 e 2017, por gênero.

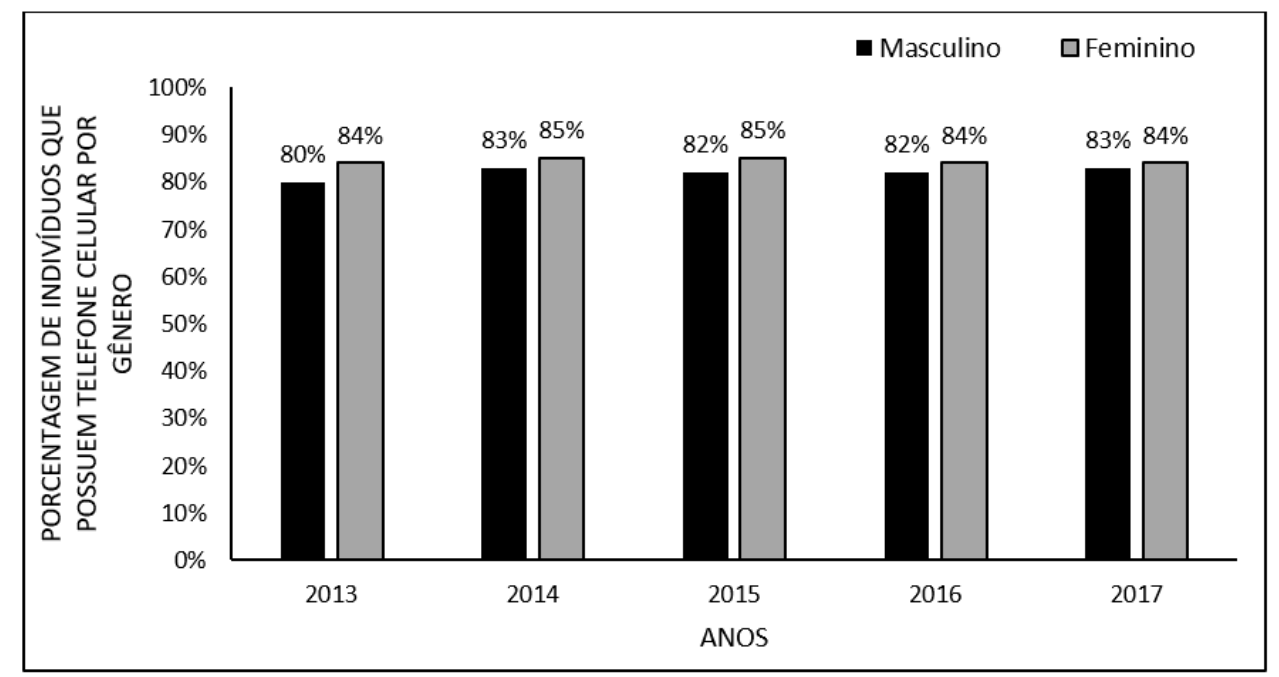

A figura 3 mostra a média da porcentagem de indivíduos que possuem telefone celular entre 2013 e 2017, por faixa etária (anos). Os maiores números encontram-se, estão na faixa de 25 a 34 anos (93\%), seguidos das faixas etárias de 16 a 24 e de 35 a 44 (ambos com $91 \%$ ), 45 a 59 e 10 a 15 (67\%) e 60 anos ou mais (65\%).

Figura 3 Mostra a média da porcentagem de indivíduos que possuem telefone celular entre 2013 e 2017, por faixa etária (anos).

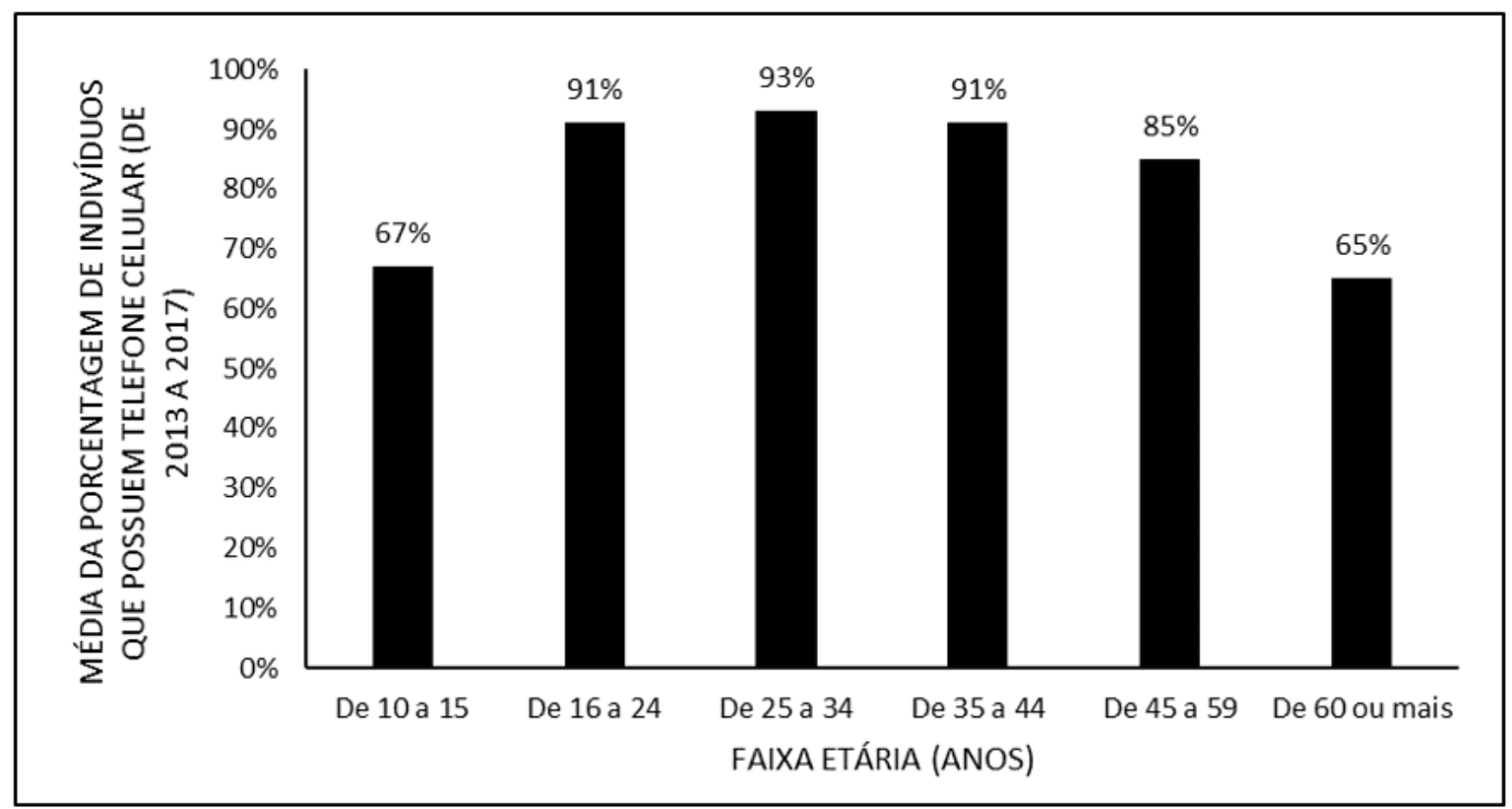

RC: 42619

Disponível em: https://www.nucleodoconhecimento.com.br/tecnologia/utilizacao-individual 
As porcentagens de indivíduos que possuem telefone celular, quando analisado por tipos de plano (pré ou pós pagos), distribuem-se pelas regiões do Brasil, gênero e pela faixa etária (anos). Em todas as categorias existem mais linhas pré-pagas do que póspagas (Tabela 1).

Tabela 1 Mostra as porcentagens de indivíduos que possuem telefone celular por tipos de plano, distribuídos pelas regiões do Brasil, pelo gênero e pela faixa etária (anos).

\begin{tabular}{|c|c|c|c|}
\hline & & Pré-Pago & Pós-Pago \\
\hline \multirow{5}{*}{ 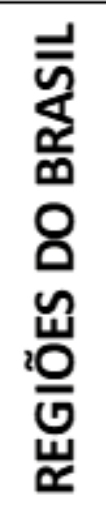 } & Sudeste & $72 \%$ & $25 \%$ \\
\hline & Nordeste & $82 \%$ & $11 \%$ \\
\hline & Sul & $77 \%$ & $22 \%$ \\
\hline & Norte & $86 \%$ & $12 \%$ \\
\hline & Centro-Oeste & $77 \%$ & $22 \%$ \\
\hline \multirow{2}{*}{ 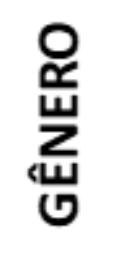 } & Masculino & $76 \%$ & $21 \%$ \\
\hline & Feminino & $78 \%$ & $19 \%$ \\
\hline \multirow{6}{*}{ 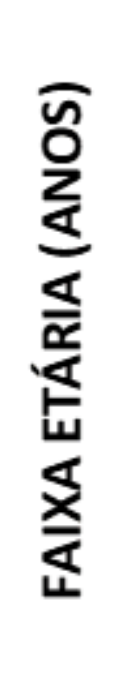 } & De 10 a 15 & $85 \%$ & $10 \%$ \\
\hline & De 16 a 24 & $83 \%$ & $15 \%$ \\
\hline & De 25 a 34 & $77 \%$ & $21 \%$ \\
\hline & De 35 a 44 & $75 \%$ & $23 \%$ \\
\hline & De 45 a 59 & $74 \%$ & $23 \%$ \\
\hline & De 60 ou mais & $72 \%$ & $23 \%$ \\
\hline
\end{tabular}


A figura 4 mostra a média da porcentagem de usuários de telefone celular, por efetuar e receber chamadas telefônicas nos últimos três meses dos anos entre 2013 a 2017, por região do país. As regiões do Brasil que mais efetuaram e receberam chamadas telefônicas, foram o Sudeste e o Sul (ambos com 96\%), seguidos do Nordeste (95\%), Centro-Oeste (95\%) e Norte (93\%).

Figura 4 Mostra a média da porcentagem de usuários de telefone celular, por efetuar e receber chamadas telefônicas nos últimos três meses dos anos entre 2013 a 2017, por região do país.

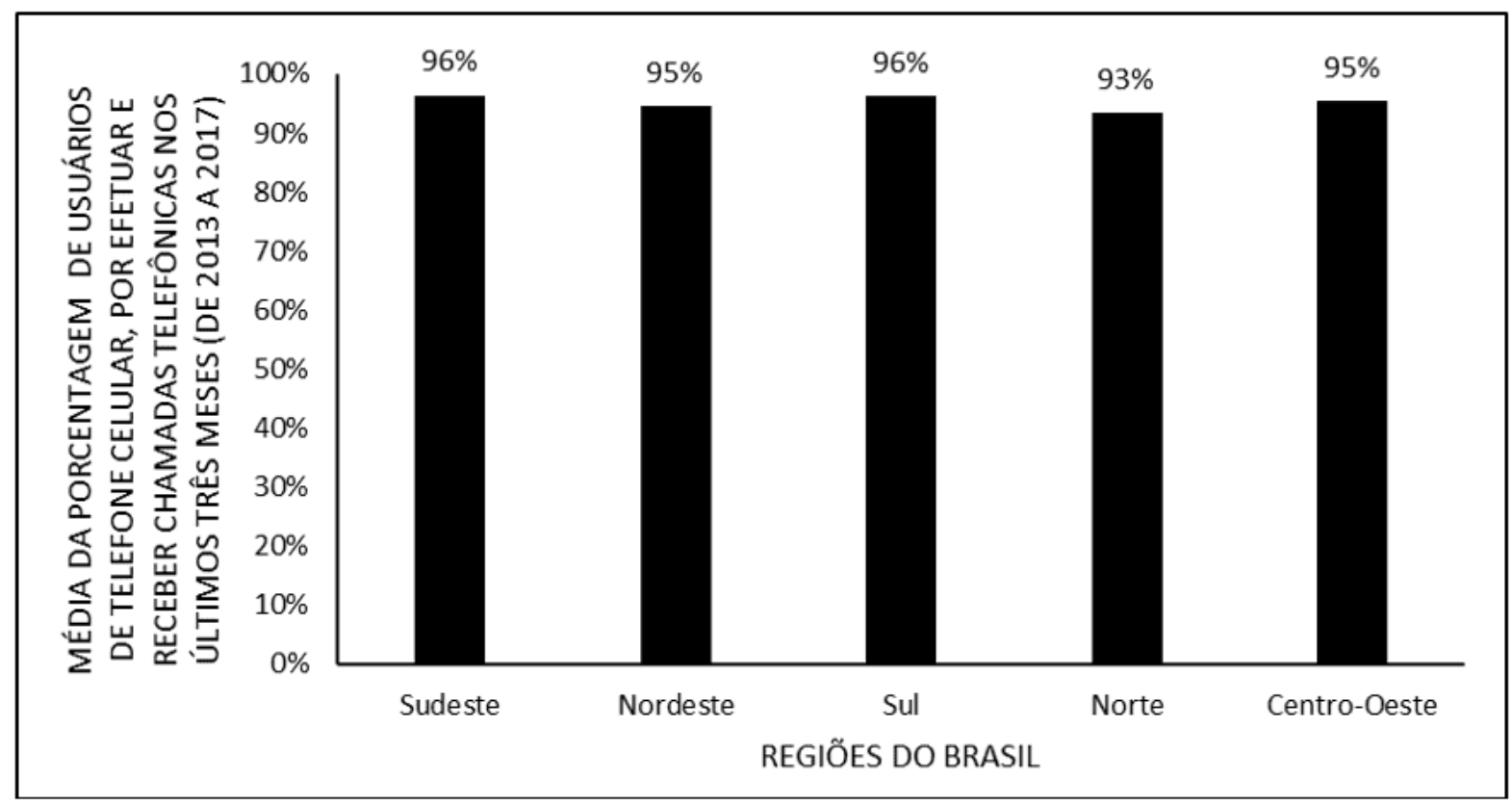

A figura 5 mostra a média da porcentagem de usuários de telefone celular, por efetuar e receber chamadas telefônicas nos últimos três meses dos anos entre 2013 a 2017 , por gênero. O público feminino é quem mais faz e recebe chamadas (em média $96,2 \%)$ quando comparado com o público masculino (94,8\%). Entre os anos nota-se uma queda na porcentagem de ligações feitas e recebidas. 
Figura 5 Mostra média da porcentagem de usuários de telefone celular, por efetuar e receber chamadas telefônicas nos últimos três meses dos anos entre 2013 a 2017, por gênero.

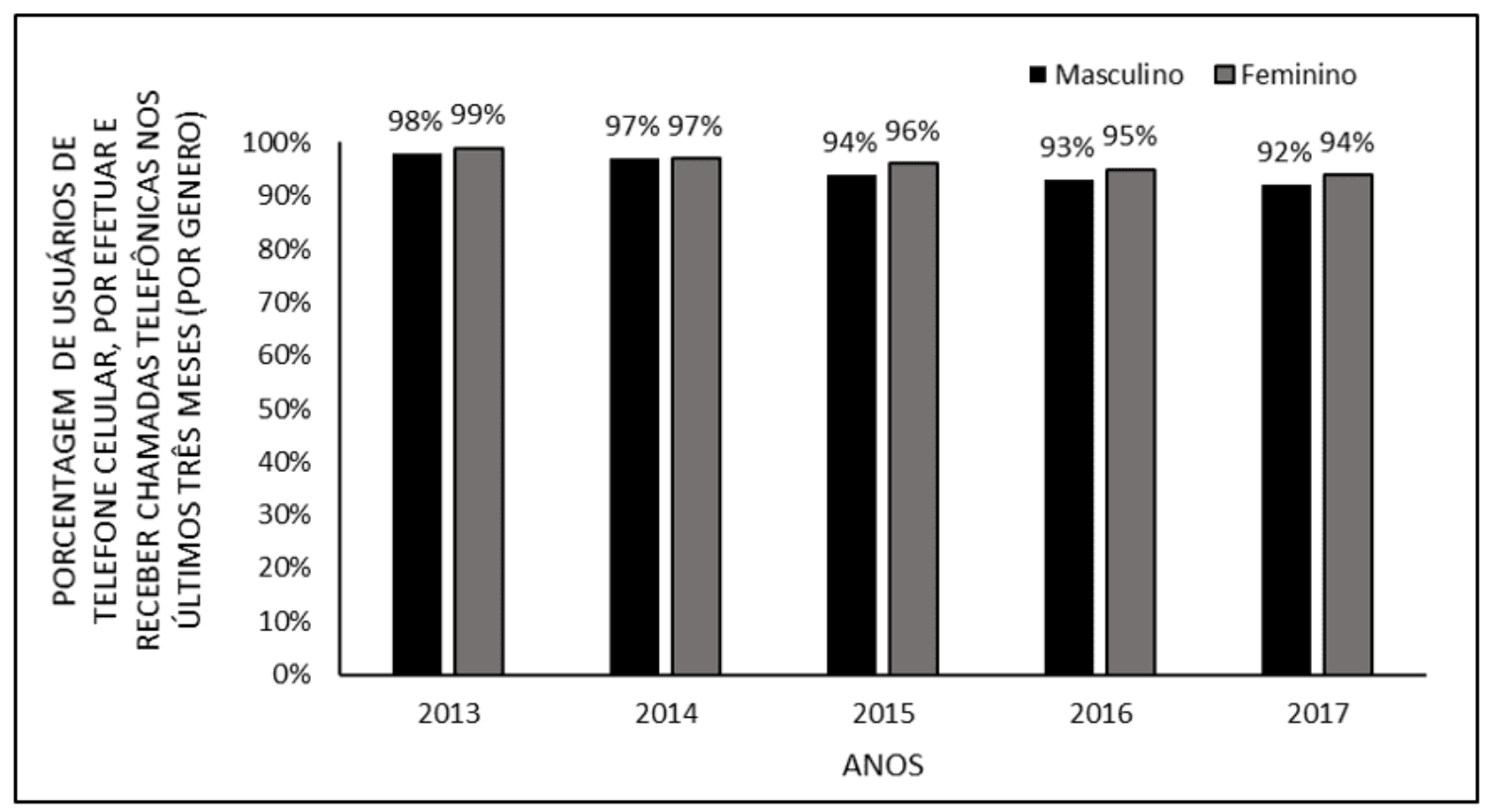

A figura 6 mostra a média da porcentagem de indivíduos por efetuar e receber chamadas telefônicas nos últimos três meses, entre 2013 e 2017, por faixa etária (anos). A faixa entre 25 a 34 e de 45 a 59 anos (ambos com 98\%), são os maiores efetuadores e receptores de chamadas telefônicas, seguidos de 35 a 44 anos (97\%), 60 anos ou mais (97\%) e de 10 a 15 anos (83\%). 
Figura 6 Mostra a média da porcentagem de indivíduos por efetuar e receber chamadas telefônicas nos últimos três meses, entre 2013 e 2017, por faixa etária (anos).

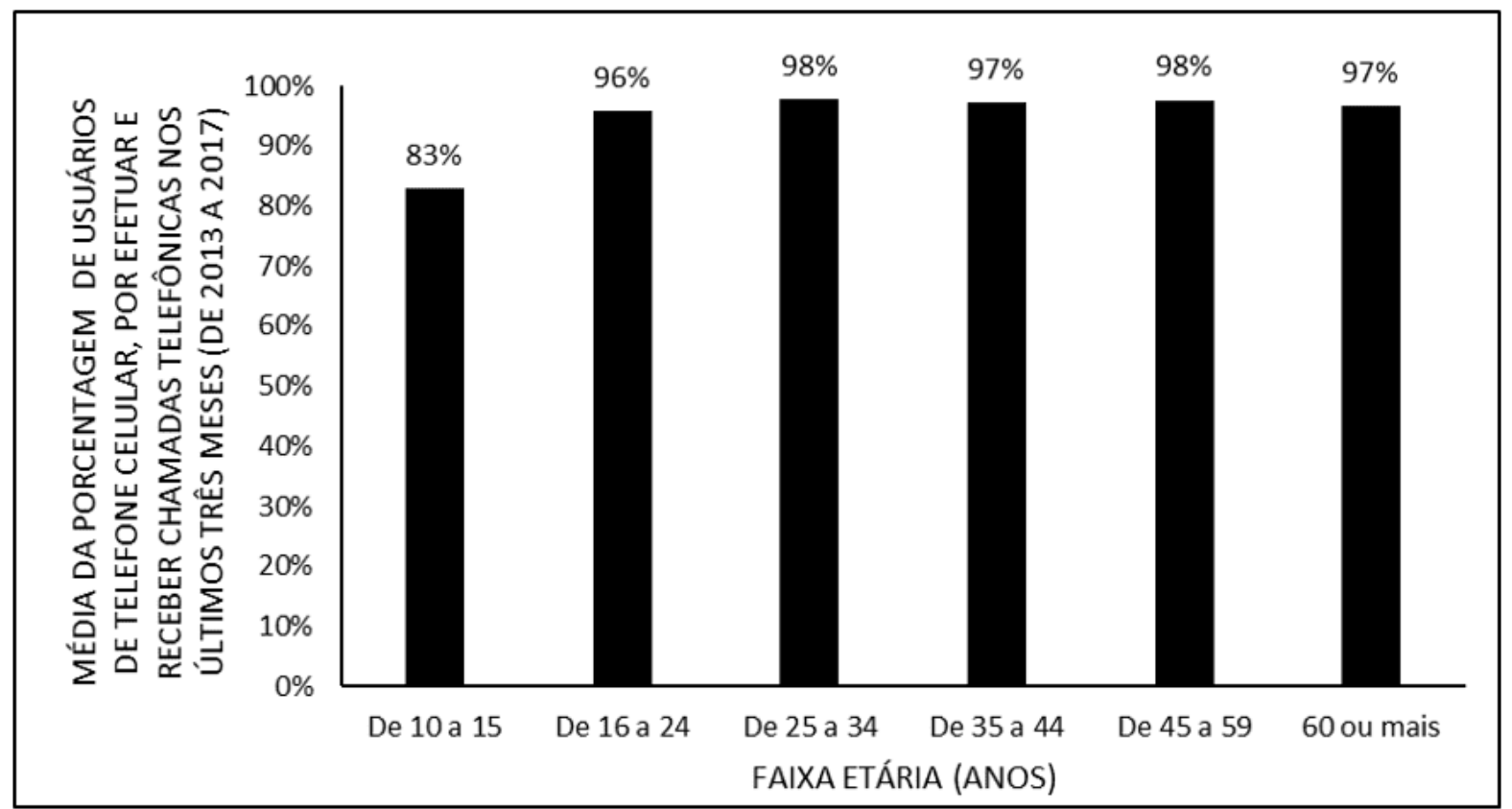

A figura 7 mostra a média da porcentagem de indivíduos por acesso as redes sociais nos últimos três meses, entre 2013 e 2017, por regiões do Brasil. O Sudeste possui maior índice (54\%), seguido do Centro-Oeste (52\%), Sul (49\%), Norte $(47 \%)$ e Nordeste (44\%). 
Figura 7 Mostra a média da porcentagem de indivíduos por acesso as redes sociais nos últimos três meses, entre 2013 e 2017, por regiões do Brasil.

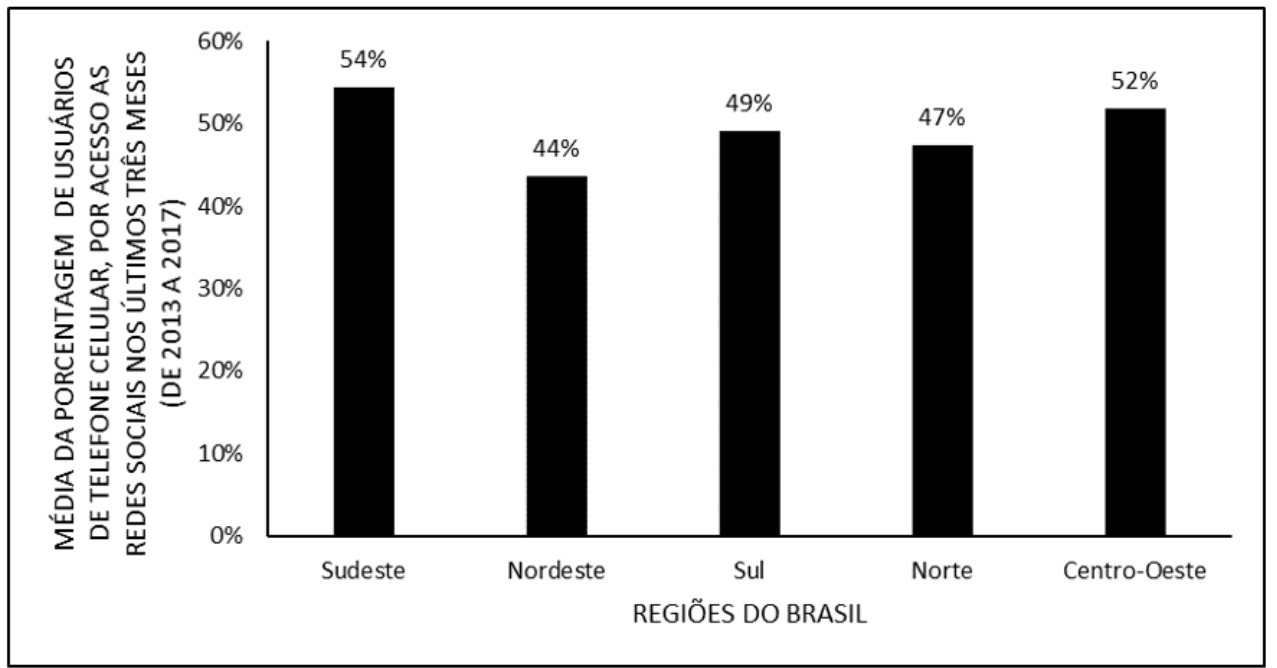

A figura 8 mostra a porcentagem de indivíduos por acesso as redes sociais nos últimos três meses, entre 2013 e 2017, por gênero. O público feminino é quem acessa as redes sociais (em média 50,8\%) quando comparado com o público masculino (49\%). Entre os anos nota-se um aumento gradual no uso das redes sociais via celular, em ambos os gêneros.

Figura 8 Mostra a mostra a porcentagem de indivíduos por acesso as redes sociais nos últimos três meses, entre 2013 e 2017, por gênero.

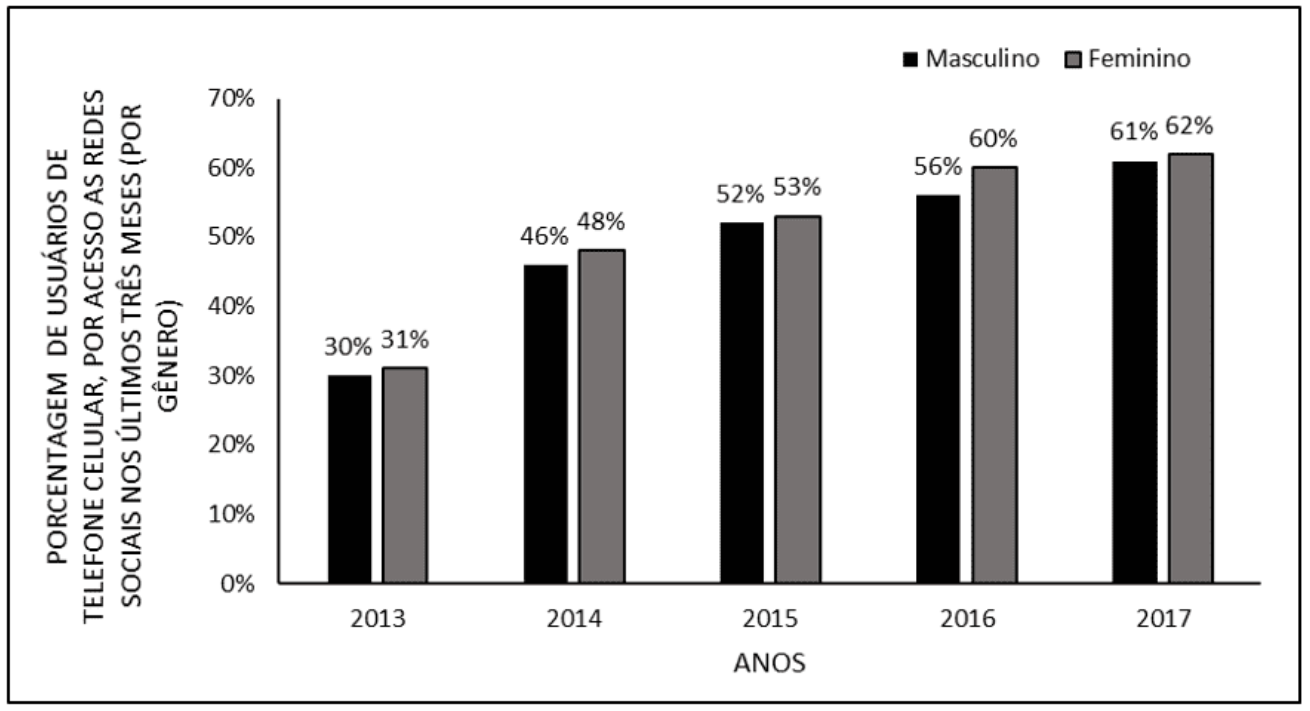


A figura 9 mostra média da porcentagem de indivíduos por acesso as redes sociais nos últimos três meses, entre 2013 e 2017, por faixa etária (anos). A faixa com maior índice de acessos é a de 16 a 24 (78\%), seguidos de 25 a 34 (66\%), 10 a 15 (62\%), 35 a $44(48 \%), 45$ a $59(29 \%)$ e 60 anos ou mais (11\%).

Figura 9 Mostra média da porcentagem de indivíduos por acesso as redes sociais nos últimos três meses, entre 2013 e 2017, por faixa etária (anos).

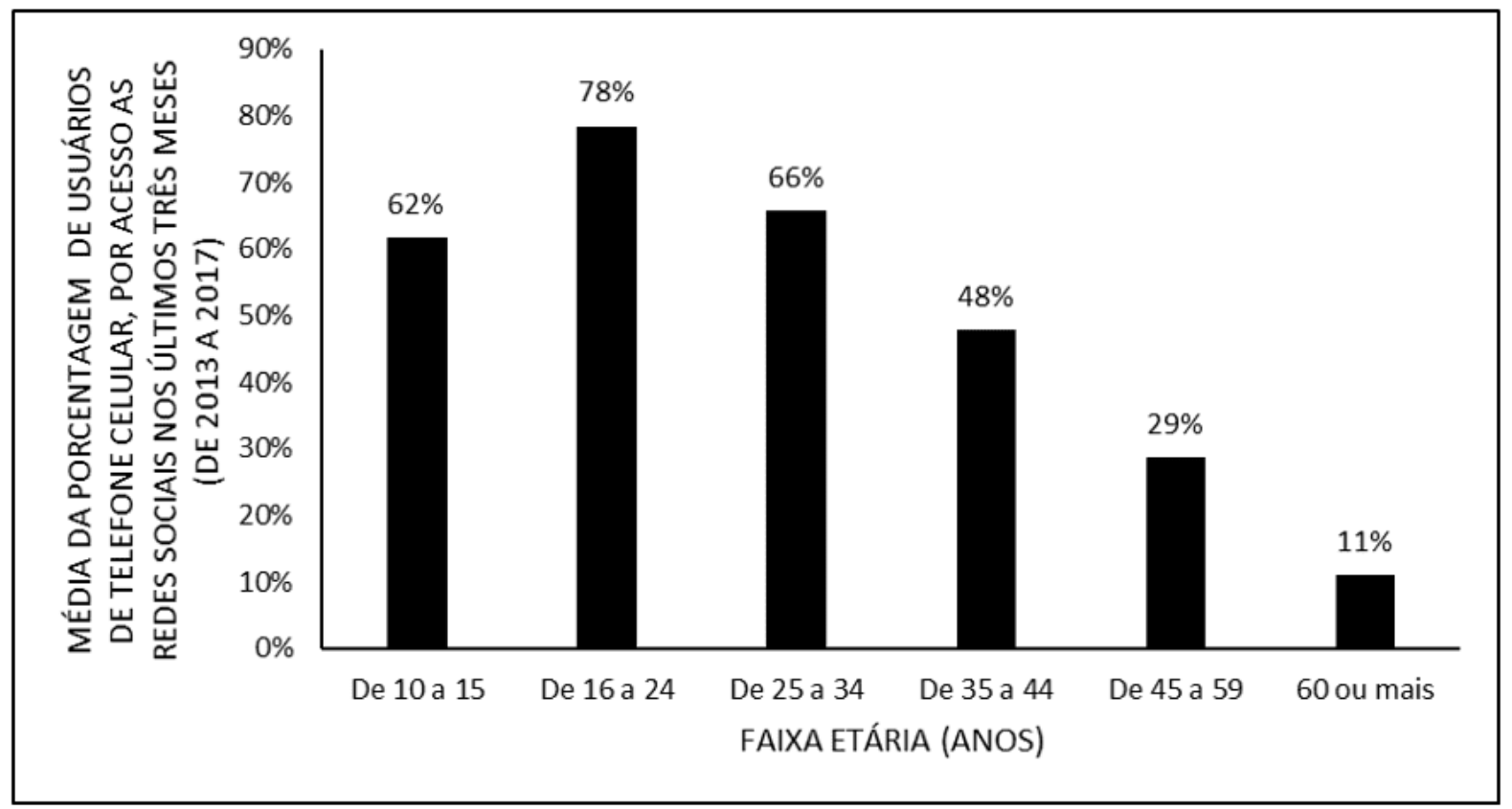

A figura 10 mostra a média da porcentagem de indivíduos por busca de informações nos últimos três meses, entre 2013 e 2017, por regiões do Brasil. O maior índice de busca de informações foi no Sudeste $(52 \%)$, seguido do Centro-Oeste $(49 \%)$, Sul $(46 \%)$ e o Nordeste junto ao Norte (ambos com $39 \%$ ). 
Figura 10 Mostra a média da porcentagem de indivíduos por busca de informações nos últimos três meses, entre 2013 e 2017, por regiões do Brasil.

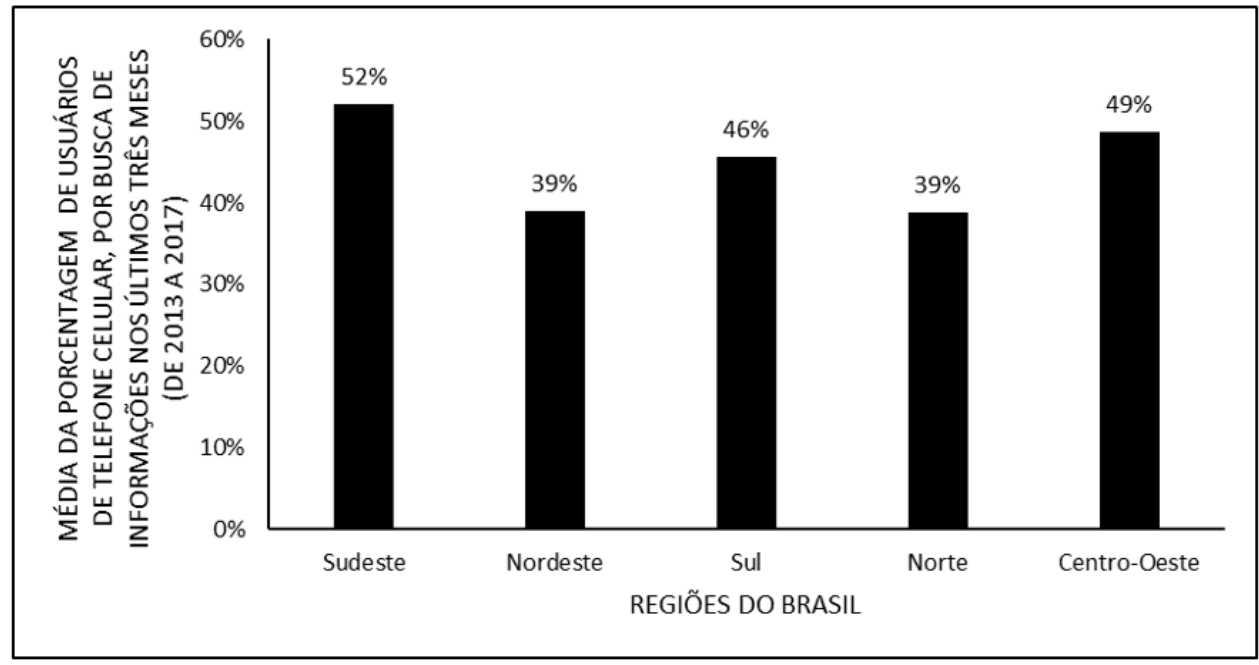

A figura 11 mostra a porcentagem de indivíduos por busca de informações nos últimos três meses, entre 2013 e 2017, por gênero. Nos dois primeiros anos (2013 e 2014) os gêneros são parecidos em relação a porcentagem. Nos anos seguintes o público masculino mostra maior índice de busca por informações. Em ambos os gêneros ocorreu um aumento no uso do celular para busca de informações neste período.

Figura 11 Mostra a porcentagem de indivíduos por busca de informações nos últimos três meses, entre 2013 e 2017, por gênero.

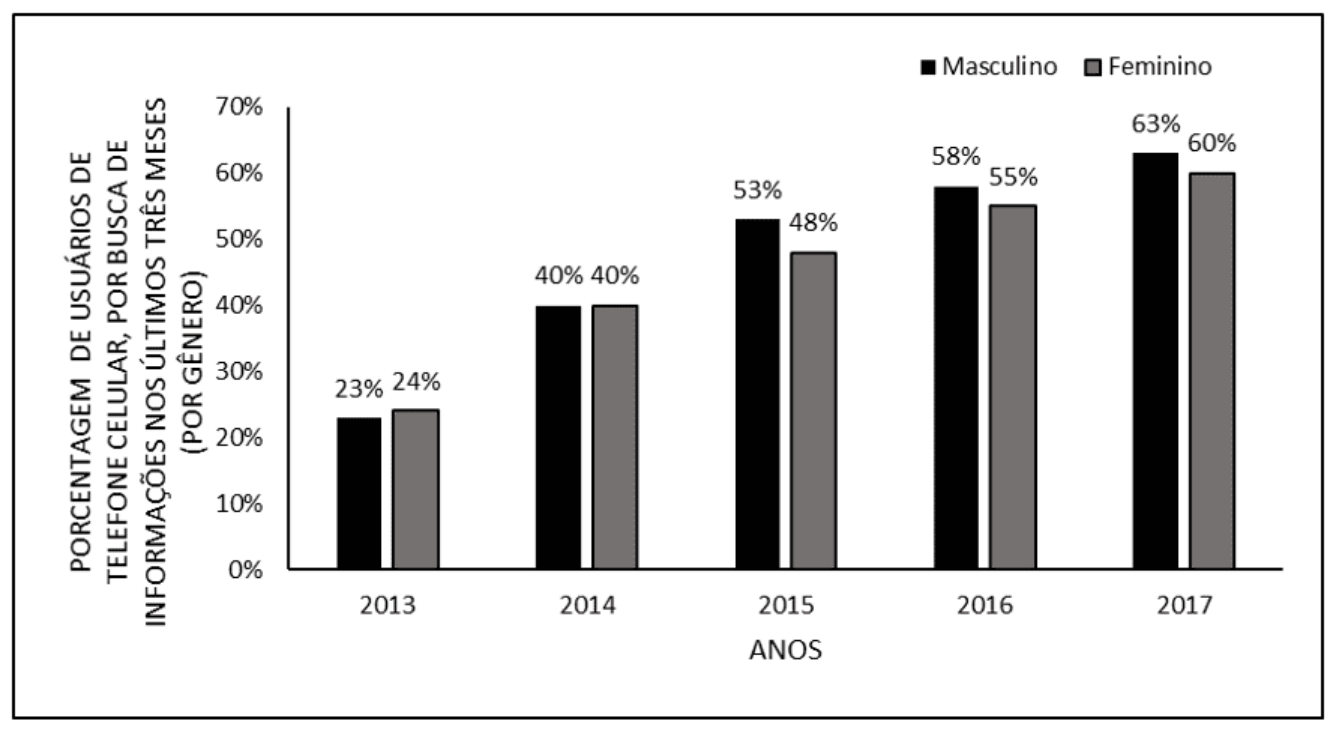


A figura 12 mostra a média da porcentagem de indivíduos por busca de informações nos últimos três meses, entre 2013 e 2017, por faixa etária (anos). O maior índice de busca de informações é da faixa etária de 16 a 24 (71\%), seguidos de 25 a $34(61 \%)$, 10 a $15(55 \%), 35$ a 44 (45\%), 45 a $59(28 \%)$ e 60 anos ou mais (11\%).

Figura 12 Mostra a média da porcentagem de indivíduos por busca de informações nos últimos três meses, entre 2013 e 2017, por faixa etária (anos).

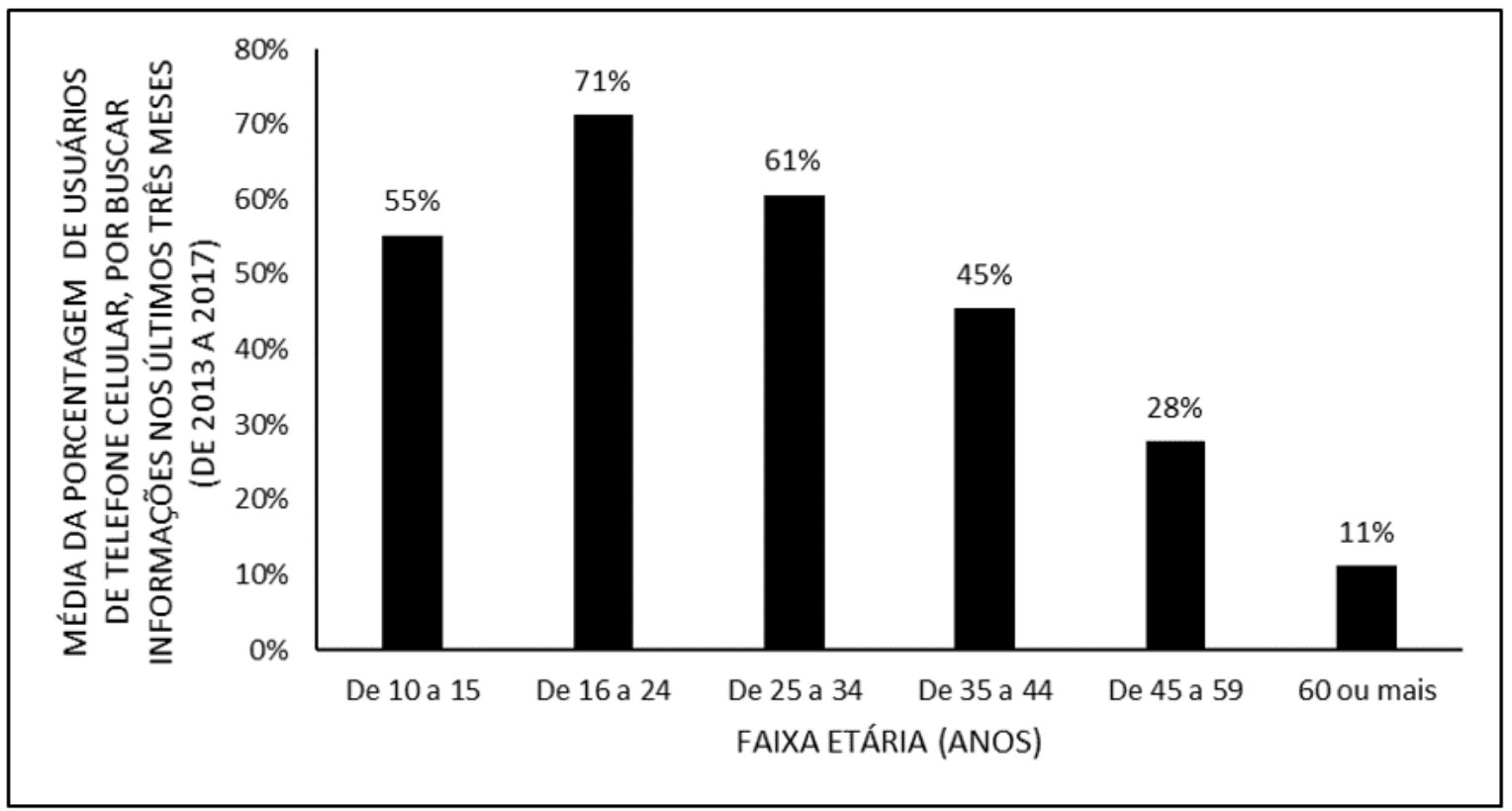

\section{DISCUSSÃO}

O contraste percentual de aparelhos celulares entre as regiões do Brasil (figura 1) existe, porém não parece ser tão equidistante. O número de celulares e de celulares inteligentes (smartphones) cresceu no país, superando a telefonia móvel em 2004 e os celulares comuns em 2013. Existe uma tendência mundial para que esta curva de crescimento continue, o que ocorre também nas regiões brasileiras (BORGES et al., 2016).

A pequena diferença percentual feminina do uso do celular (figura 2 e figura 5) pode dever-se a mudança que os fabricantes fizeram no design destes aparelhos. Os modelos e as tecnologias passaram a ser desenvolvidas para serem mais atraentes 
ao gênero feminino, por uma visão mercadológica. $O$ foco na mulher, incluindo os acessórios, pode estar ligado ao status social, daí a feminilização dos celulares (AGUIAR et al., 2014).

A maior posse de aparelhos entre os 25 e 44 anos (figura 3) deve-se a pessoas jovens, estudantes ou recém-formados que apresentam maior familiaridade com as tecnologias modernas (FONSÊCA et al., 2018). Empreendedores, dentro deste grupo, utilizam o aparelho para se conectar a fornecedores e clientes. O maior número de ligações nesta faixa (figura 6) ocorre devido a posse e objetivos de uso (ARAUJO; JUNIOR, 2018).

Tem-se maior utilização de planos pré-pagos (Tabela 1) por controle de quanto é gasto mensalmente (principalmente nas famílias de baixa renda). O plano pós-pago é geralmente usado por empresas ou grupo de indivíduos (familiares) que fazem ligações com frequência (BARCELOS et al., 2015).

As telecomunicações iniciaram-se no Sudeste, especificamente em Belo Horizonte (MG) (VILHEINA; LOPES, 2017). O sudeste e sul efetuam e rebem mais chamadas telefônicas em relação as outras regiões (figura 4), provavelmente por conta de serem regiões metropolitanas, com maior número de habitantes e empresas (SOARES, 2015).

As regiões Sudeste e Centro-Oeste, tem maior percentual de indivíduos que acessam as redes sociais (figura 7), provavelmente porque o Sudeste é populoso (com $86.949,714$ habitantes), tem uma grande área urbana, e industrias. Por estes fatores é mais desenvolvida tecnologicamente e, portanto, acaba utilizando mais essas ferramentas de comunicação (FERRAZ, 2019). Nestes estados há também um maior uso dos aparelhos para busca por informações (figura 10). Estes acessos visam apenas diversão como, por exemplo, visualização de memes (COELHO E MARTINS, 2018) ou busca de informações básicas de saúde (GONÇALVES et al., 2019).

Mulheres que são empreendedoras tendem a se comunicar mais do que o outro gênero (figura 8). As redes sociais favorecem trocas de informações, vendas de 
produtos, compra de insumos e estimula a competitividade. As mulheres que empreendem tendem a usar mais as redes sociais, não só como ferramenta de trabalho, mas também como comunicação social (MACHADO e JESUS, 2010). A busca por informações se equipara entre mulheres e homens (figura 11). A diferença aparece quando analisamos o conteúdo da busca. Mulheres acessam mais conteúdo sobre beleza e homens sobre tecnologia (ROCHA e MILL, 2018).

A faixa etária de 45 a 60 anos ou mais, tem menor índice de utilização em redes sociais (figura 9), provavelmente porque cada faixa etária seu comportamentos diferentes, os idosos por exemplo, não utilizam o meio virtual por não serem nativos da tecnologia, ou seja, não estarem habituados, já que nasceram bem antes do surgimento dessa tecnologia. O posto se dá com faixas etárias mais jovens (SILVA et al., 2019). A maior busca de informações pelas faixas etárias mais jovens (figura 12) pode estar vinculada à vida escolar e acadêmica. Existe um aumento uso pedagógico da internet fazendo o discente buscar informações de maneira ágil, via aparelho celular (QUEIROZ, 2018).

\section{CONCLUSÃO}

O gênero feminino é majoritário em posse de aparelhos, em efetuar e receber chamadas e acessos as redes sociais. Os proprietários e usuários são jovens e adultos entre 16 e 34 anos. Observa-se que há um aumento na utilização de celulares nas regiões Sul e Sudeste no país, mostrando uma desigualdade em relação à tecnologia. No Brasil não há fortes projetos para combater essa desigualdade social, limitando $o$ acesso à informação e, consequentemente, oportunidade de discernimento ao cidadão comum.

\section{REFERÊNCIAS}

AGUIAR, F. H. O; BARRICHELLO, MORANO, A.; R. S. SILVA, D. L.; OLIVEIRA, G. M.; SEABRA, V. B. Avaliação da Usabilidade de Telefones Celulares no Mercado Brasileiro: Gênero, Idade, Escolaridade e Renda Familiar têm alguma Influência? RAIMED - Revista de Administração IMED, 4(2): 144-160, 2014. 
ARAUJO, F. S. G.; JUNIOR, S. M. Empreendedorismo E Turismo: Caracterização Do Perfil Empreendedor Do Setor De Turismo No Rio Grande Do Norte. Turismo: Estudos \& Práticas, v. 7, n. 1, p. 112-135, 2018.

BARBOSA, J. R. A. Reflexões Sobre Desigualdades Regionais Referentes Ao Uso Da Internet No Território Brasileiro. Revista Contexto Geográfico, v. 3, n. 5, p. 75 - 81, 2018.

BARCELOS, R. H.; ESTEVES, P. S.; PIEGAS, B. K. Fatores de Escolha e Troca de Operadora de Telefonia Celular no Brasil: $O$ que pesa na Lealdade dos Consumidores? RACEF - Revista de Administração, Contabilidade e Economia da Fundace. v. 6, n. 2, p. 47-63, 2015.

BORGES, G.R.; PETRY, J.F.; MACHADO, D.D.P.N.; RASIA, I.C.R.B. Um estudo preliminar dos fatores perceptivos subjacentes da preferência dos brasileiros por aparelhos celulares. Perspectivas em Gestão \& Conhecimento, v. 6, n. 1, p. 255269, 2016.

CARRANO, P. C. R. Redes sociais de internet numa escola de ensino médio: entre aprendizagens mútuas e conhecimentos escolares. Perspectiva, v. 35, n. 2, p. 395421, 2017.

COELHO, C.; MARTINS, R. Memes de internet, visualidades e discurso humorístico. Revista Digital do LAV, vol. 11, n. 1, p. 121-139, 2018.

FERRAZ, A. R. R. S. A Utilização da Internet Feita Por Crianças Com Idade Entre 5 e 10 Anos. 2019. 75p. (Graduação). Trabalho De Conclusão De Curso, Universidade Federal de Alagoas, Maceió.

FONSÊCA, P. N. et al. Uso de Redes Sociais e Solidão: Evidências Psicométricas de Escalas. Arquivos Brasileiros de Psicologia, v. 70, n. 3, p. 198-212, 2018. 
GONÇALVES, R.C. et al., Qualidade de páginas brasileiras da internet que disponibilizam informações sobre micoses humanas. Multi-Science Journal, v. 2, n. 1, p.23-32, 2019.

GUTIERREZ, R.M.V.; CROSSETTI, P.A. A indústria de telequipamentos no Brasil: evolução recente e perspectivas. BNDES Setorial, n. 18, p. 23-90, 2003.

IBGE. Pesquisa Nacional por Amostra de Domicílio Contínua. Diretoria de Pesquisas, p.14, 2016. Disponível em < https://biblioteca.ibge.gov.br/visualizacao/livros/liv101543.pdf> Acesso em 29/08/2019.

LIRA et al. Uso de redes sociais, influência da mídia e insatisfação com a imagem corporal de adolescentes brasileiras. Jornal brasileiro de psiquiatria, v. 66, n. 3, p. 164-71, 2017.

MACHADO, H.V.; JESUS, M.F. Efeitos da participação de mulheres em redes sociais: um estudo em um conselho de mulheres executivas. Revista Economia \& Gestão. v. 10, n. 24, 2010.

QUEIROZ, J.S. A internet como recurso pedagógico: comunicação e interação para além dos muros da escola. ARETÉ, v. 11, n. 23, 2018.

ROCHA, E.G.; MILL, D. Análise em gênero, educação e tecnologias nas preferências e percepção de adolescentes em acesso à Internet. Estud. pesqui. Psicol., v. 18, n. 2, p. 569-587, 2018.

SCHUMANN, C. M.; COUTINHO, C. V.; MARINO, E. R. O Uso Das Redes Sociais Na EaD. Revista Cesuca Virtual: Conhecimento Sem Fronteiras, v.2, n. 4, p. 106-116, 2015

SILVA, F. A. B.; ZIVIANA, P.; GHEZZI, D. R. As Tecnologias Digitais E Seus Usos Instituto de Pesquisa Econômica Aplicada - ipea, 2019. 54p. 
SIQUEIRA, T. C.; OLIVEIRA, S. C. Desenvolvimento de uma Extensão Telefônica Remota utilizando a Rede de Telefonia Celular GSM. Revista de Engenharia e Pesquisa Aplicada, v. 1, n. 1, p. 51-59, 2016.

SOARES, P. R. Regiões metropolitanas ou aglomerações urbanas? Contribuição para o debate no Rio Grande do Sul. Ensaios FEE, v. 36, n. 2, p. 323-342, 2015

SOUZA, W. C. Construtor De Sistemas Web. 2018. 53p. (Graduação). Trabalho De Conclusão Do Curso Tecnológico Em Análise E Desenvolvimento De Sistema, Instituto Federal De Santa Catarina, Gaspar, SC.

TORRES, C. A Bíblia Do Marketing Digital: Tudo O Que Você Queria Saber Sobre Marketing E Publicidade Na Internet E Não Tenha A Quem Perguntar Editora Novatec, 2018. 350p.

VILHENA, P. E. R.; LOPES, M. S. Retrato em branco e preto: memórias de uma sala de audiências no início da década de 60 . Revista de direito do trabalho, v. 43, n. 173, p. 109-136, 2017.

Enviado: Dezembro, 2019.

Aprovado: Dezembro, 2019. 